\title{
Advances in composites applied to masonry
}

\author{
L. Binda
}

Published online: 16 October 2014

(C) RILEM 2014

This Thematic Issue presents an overview of current research on composite materials as applied to masonry constructions and structural components. It is the result of work and international collaboration among members of the 223 MSC RILEM Technical Committee "Masonry strengthening with composite materials" (2007-2013), together with their research groups.

Starting from a general discussion of the most critical aspects and problems still open in the field, highly topical open issues are then analysed in the following papers. They cover aspects for which clarification is urgent and essential in this context, in order to increase proper knowledge, for reasonable, reliable applications in existing buildings. Taking into account that strengthened masonry structures frequently belong to historical centers it is very important to avoid possible failures due to inappropriate or incompatible application of the techniques. Experimental approaches and modeling procedures calibrated on experimental bases, both analytical and numerical, are proposed, providing those studies, in most cases, a relevant contribution to the few and still incomplete available standards.

The subjects included in the Thematic Issue include:

L. Binda (两)

Politecnico di Milano, Milan, Italy

e-mail: luigia.binda@polimi.it (a) Interventions on historical buildings (paper 1): the complex approach to historical masonry requires deep knowledge of the relative constructive systems and specific awareness of the capability and limitations of possible intervention techniques, taking into account the need for compliance with preservation criteria. Some typical applications to case studies are critically discussed, providing examples of possible solutions for specific problems requiring strengthening, repair or rehabilitation by using composites, that is with fiber reinforced polymers (FRP) or, more recently, steel reinforced grouts (SRG) textiles.

(b) Bond (papers 2, 3, 4): bond is one the most important aspects to be clarified as it is crucial for the effectiveness of interventions. FRP textiles applied with wet lay-up system are the most studied in this field. Problems of modeling FRP-to-clay brick bond are addressed in paper 2 , by comparing various approaches, analytical and numerical simulations, and a large number of experimental results. The papers 3 and 4 report recent trends on bond with different materials that are used in the field, often focusing on experimental works evaluating the effectiveness of matrixes as alternative to epoxy resins, on which there is still little research. Paper 3 describes the use of innovative flexible polymers favoring better compound behavior 
between substrate and reinforcement systems. Paper 4 discusses the use of inorganic mortars (mainly cement-free, for better compatibility with masonry) for application of steel fibers (SRG) and carbon or basalt textile reinforced mortar (TRM) on clay or stone bricks, and using various setups and surface preparations.

(c) Durability (papers 5, 6): despite the considerable importance of this topic for applications to existing buildings, few contributions are available in the literature. These two papers thus make an important input, discussing the influence of water and temperature in deterioration phenomena, such as freeze-thaw (paper 5) and salt crystallization and thermal ageing (paper 6). Mechanical performance is checked by bond procedures (shear tests in paper 5, and pull-off tests in paper 6 ), on clay bricks reinforced with glass (paper 5) or carbon FRPs (paper 6). Paper 6 considers different types of bricks (also reinforced with polymers as matrices, as in paper 3 ) and the presence of mortar joints.

(d) Strengthening of structural components (papers 7-11): these papers concern recent studies on the application of various composites (FRP, SRG, TRM; bars, cords) to improve the mechanical behavior of all typical components belonging to masonry structures, i.e., arches and vaults (paper 7), columns and pillars (papers 8 , 9, 10), and walls (paper 11). Paper 7 presents a recent study on basalt TRM applied to stone masonry arches, and also includes analytical and numerical comparisons. Papers on columns focus on various strengthening systems (glass FRP textiles with or without transverse carbon bars, or glass TRM fixed with spikes; papers 8 , 9) and steel cords (paper 10) applied to different section shapes and masonry types (stonework, papers 8, 9; clay brick, paper 10), taking into account both experimental (compression tests) and analytical approaches. Finally, paper 11 compares the effectiveness of various reinforcing systems and materials applied to modern masonry (infill hollow-tile walls subjected to out-of-plane forces), adding the discussion on the use of natural fibers (such as flax and hemp), which are quite recent and promising in the field.

It should be noted that the whole set of papers covers a wide range of material types, problems, applications and approaches. Lastly, the papers complement each other, providing a complete, updated report of the state of research in the field. 